\title{
Evaluation of the potential control of natural compounds against anthracnose in mango (Mangifera indica L. Cv. tommy atkins)
}

\begin{abstract}
Anthracnose produced by Colletotrichum gloeosporioides is a post-harvest mango disease causing big economic losses worldwide. Plant pathogens have increased their resistance to chemical fungicides. The use of natural formulations for disease control represents a healthier alternative. Therefore, testing new natural antimicrobial agents is necessary.

Several natural agents for phytopathogen control have been described. Their effectiveness depends on various factors such as their composition, concentration and the environment. We evaluated the antifungal activity of organic crude extracts of Citrus x paradisi (grapefruit), Citrus reticulata (tangerine) and Citrus aurantium (sour orange) and a treatment with chitosan in mango fruits cv. Tommy Atkins against $C$. gloeosporioides.

The extracts obtained with hexane from dried sour orange peels had a considerable fungicidal effect on the radial growth of the fungus. Also, the parameters evaluated in mango fruits demonstrate that the chitosan treatment delays the development of symptoms of anthracnose.
\end{abstract}

Keywords: anthracnose, Colletotrichum gloeosporioides, citrus peel extracts, chitosan, mango fruit
Volume 5 Issue 2 - 202I

\author{
José Efraín Ramírez-Benítez,' Norma Laura \\ Rodríguez-Ávila, ${ }^{2}$ Gabriel Lizama-Uc, ${ }^{3}$ Ángel \\ Virgilio Domínguez May, ${ }^{4}$ Héctor Octavio \\ Guerrero Turriza, ${ }^{2}$ Jorge Román Herrera- \\ Flores, ${ }^{\prime}$ Abigail Malerva-Díaz ${ }^{2}$ \\ 'Facultad de Ciencias Químico Biológicas, Universidad \\ Autónoma de Campeche, México \\ ${ }_{2}^{2} T E C N M /$ Instituto Tecnológico de Chiná, México \\ ${ }^{3}$ Instituto Tecnológico de Mérida, México \\ ${ }^{4}$ Instituto Tecnológico Superior del Sur del Estado de Yucatán, \\ México
}
Correspondence: Norma Laura Rodríguez Ávila, TECNM/ Instituto Tecnológico de Chiná, Calle II entre 22 y 28, Col. Centro, Chiná, Campeche, 24050, México, Tel +52(98I)8272082, Ext.108,Email norma.ra@china.tecnm.mx

Received: February 18, 2021 | Published: March 01, 202

\section{Introduction}

Mexico is the main exporter of mango, contributing 20.5\% to the total world in 2013. ${ }^{1}$ The search for strategies to increase the profitability of its cultivation is of increasing interest.

One of the main problems in the reduction of the sale price is the low quality of the product derived from the presence of diseases caused by contamination with microorganisms in the pre-harvest, harvest and post-harvest stages. An efficient management of the product in the postharvest period is the key factor for the successful commercialization of mango fruits, preserving its quality and modifying the speed of maturity, increasing its shelf life.

Anthracnose is the most important disease in mango production. This disease causes significant losses in mango production, and affects the quality of the fruit in the post-harvest stage of the fruit, due to the lack of phytosanitary controls during cultivation and inadequate storage management. ${ }^{2}$ Anthracnose is mainly caused by two species of phytopathogenic fungi, Colletotrichum gloeosporioides and $C$. acutatum, the first being the most common in most cases. ${ }^{3}$

The fungi of the genus Colletotrichum are one of the most important plant pathogens in the world, occurring mainly in tropical and subtropical regions. ${ }^{4}$ In order to solve this problem, a great diversity of products and methods for the control in field and postharvest were designed to prevent or cure the disease, influencing the distribution of the phytopathogen, the degree of colonization in the fruits and their subsequent deterioration.

On the other hand, the main strategy for the control of fungal diseases is the use of synthetic fungicides. However, these control agents prove to be generally costly, their residues are pollutants and cause deleterious effects on other microorganisms, causing damage to both ecological and environmental levels..$^{5-8}$
Similarly, the use of agrochemicals for disease control is regulated under strict national and international standards for phytosanitary control, which promotes the development and use of environmentally friendly and consumer-friendly production and storage strategies. Natural products have proven to be effective and prove to be a safe alternative for disease control.

The antimicrobial activity of citric alcoholic extracts and Citrus Essential Oils (CEO's) as well as numerous plant species has been well studied, proving that extracts of leaves, flowers, stems, roots, seeds and pericarp of the fruits have biological activity against various microorganisms in in vitro experiments. ${ }^{9-12}$

There are several studies that demonstrate that the chemical composition of alcoholic extracts and essential oils extracted by cold pressing are similar ${ }^{13}$ so the observations derived from the study of both sources of metabolites and their antimicrobial potential is of great importance. In agar diffusion and culture media (agar dilution) studies, the antifungal potential has been demonstrated for various crude vegetable extracts. ${ }^{13-18}$

Therefore, the first objective of this research was, to evaluate the effectiveness of citrus extracts grown in the State of Campeche, Mexico, in the control of anthracnose in mango fruits. Organic extracts were obtained from dried peels of Citrus x paradisi, $C$, reticulata and C. aurantium and evaluated using the agar dilution bioassay in the control of C. gloeosporioides.

There are different mechanisms at postharvest level to control microorganisms such as the addition of inhibitory agents (these being salts or antibiotics), heat treatments, irradiation, nitrogen sweeps, aluminum coatings, drying and vacuum storage. Protective biopolymer coatings have shown advantages of use in fruits and vegetables, since they are biodegradable and sustainable because of agroindustrial and food residues, and in some cases the coating is edible and harmless to the consumer. ${ }^{19}$ 
Organic coatings are especially important because they create a physical barrier to gases by producing a modified oxygen-reducing atmosphere (avoiding oxidation) and by increasing the concentration of carbon dioxide on the surface of the product. ${ }^{21}$

Several studies report the use of chitosan (deacetylated chitin) in the elaboration of edible films to conserve food. Chitosan films have been shown to be impervious to oxygen, aromas and oils, in addition to promoting the integrity, appearance, texture and brightness of the fruit. ${ }^{22-26,16}$ Chitosan has the ability to adhere to electronegatively charged surfaces, giving it unique biological, physiological and antimicrobial properties. ${ }^{25,27}$ The biological activity of this compound depends on a number of factors, including the degree of deacetylation, molecular weight, $\mathrm{pH}$ of the medium and temperature. Chitosansensitive fungi present inhibition of spore germination, morphological and ultrastructural alterations of hyphae, as well as reduction in the production of toxins. In addition, chitosan has antimicrobial capacity, due to the interaction of chitosan with the bacterial cell membrane, through amino groups in the polymer, causing alterations in proteins and other components of the cell membrane..$^{28,29}$

Therefore, in order to complement this study and to have the experimental bases that allow the future application of citrus extracts assessed in the form of edible coatings on mango fruits, we evaluated the effect of chitosan on the protection of fruits of mango against the development of anthracnose symptoms under postharvest storage conditions

\section{Materials and methods}

\section{Fungal strains}

Strains of Colletotrichum gloeosporioides were isolated from sections of mango peel (Mangifera indica var. Tommy Atkins) with evident lesions of anthracnose. Each of the sections were seeded directly into nutrient medium Potato Dextrose Agar (PDA), incubated at $28{ }^{\circ} \mathrm{C}$. Spores were isolated until monosporic cultures were obtained. The purified isolates were characterized morphologically making macro and microscopic description of the pathogen, including color and form of the colony, appearance and color of the mycelium; Shape, size, segmentation and sporulation of conidia. ${ }^{4}$

To maintain pathogenicity of the fungus, periodic inoculations and reisolations from infected mango fruits were carried out Experiments were carried out using 10-15 days old cultures. For the assays, the sporangial suspension concentration was estimated using a cellcounting chamber and adjusted to $2 \times 10^{6}$ spores $\mathrm{mL}^{-1} \cdot{ }^{30}$

\section{Plant material}

Three citrus species abundant in the Yucatan Peninsula were selected: grapefruit (Citrus x paradisi), tangerine (Citrus reticulata) and sour orange (Citrus aurantium). The fruits of these species were acquired in local markets of the State of Campeche, México For the evaluation of the coatings with chitosan, mango fruits (M. indica var. Tommy Atkins) were harvested from an orchard in the community of Castamay, Campeche, Mexico with a maturation state of 3/4 (brownreddish color covering three quarters of the surface of the fruit).

After the collection, the peduncle of the fruits was cut. The selection of the fruits was carried out weighing the fruits collected, obtaining the population distribution of weights. Only fruits with a variation smaller than one standard deviation of the population mean were used (fruits, $\mathrm{X}=373.5 \mathrm{~g}, \sigma=56.8 \mathrm{~g}$ ).

In all studies, the fruits selected were washed with mild detergent and sponge, rinsed in running water and disinfected with $1.5 \%$ sodium hypochlorite solution. After disinfection, the fruits were rinsed in running water, dried with an absorbent cloth and stored under refrigeration at $4{ }^{\circ} \mathrm{C}$ until use.

\section{Preparation of plant extracts}

The sour orange, tangerine and grapefruit peels were washed and disinfected as described above. This done, they were cut with scissors in pieces of approximately $1 \mathrm{~cm}^{2}$ and dehydrated at $70{ }^{\circ} \mathrm{C}$ until obtaining a constant weight. The extraction was performed with $99 \%$ ethanol, methanol or hexane, previously grinding a known quantity of the dried samples and adding the solvent using a ratio of 1:4 and mixing using an industrial mixer for 30 mins. The flask where allowed stand for $72 \mathrm{~h}$ and mixed occasionally.

Using a millimeter mesh, the obtained extract was filtered in order to remove the greater amount of organic matter. The alcoholic extracts were allowed to settle in a separatory flask for about $1 \mathrm{~h}$, in order to obtain a clarified supernatant. The supernatant was recovered and centrifuged for $30 \mathrm{~min}$ at $3000 \mathrm{rpm}$ to complete the clarification of the extracts. The recovery of the solvent was carried out by steam distillation using a rotary evaporator until complete removal of the solvent. The crude extracts obtained were recovered and stored in sterile amber flasks at $4{ }^{\circ} \mathrm{C}$ until their use for the growth inhibition assay.

\section{Determination of antifungal activity}

Minimal inhibitory concentration (MIC) was calculated using the agar dilution method (poisoned food technique). For this purpose, PDA medium was poisoned with different concentrations of the extracts obtained, from $250 \mu \mathrm{g} / \mathrm{ml}$ to $20 \mathrm{mg} / \mathrm{ml}$. These mixtures were emptied in Petri dishes and inoculated with a strain of Colletrotrichum gloesporioides previously characterized by their high virulence and incubated at $28{ }^{\circ} \mathrm{C}$ for 20 days, verifying the absence/presence of mycelial growth and the diameter of the colonies detected both In the control as in the test assays. The results were expressed as the average diameter \pm Standard Deviation (S.D.) of mycelial growth observed over time (days 2, 5, 7, 14 and 20). Each experiment was performed in triplicate and sterile water was used as the control.

\section{Treatments of mango fruits with chitosan}

Chitosan with a deacetylation degree of $75\left(\mathrm{C}_{12} \mathrm{H}_{24} \mathrm{~N}_{2} \mathrm{O}_{9}\right)$ from shrimp shell (SIGMA. Cat. No. C3646), diluted in $0.2 \mathrm{M}$ acetic acid, $\mathrm{pH} 4$, was used to obtain a concentration of $0.25 \%$ mixing by stirring at $100{ }^{\circ} \mathrm{C}$ for $60 \mathrm{~min}$, to be subsequently filtered with gauze and used immediately for the treatment of the fruits.

The mango fruits were submerged in the chitosan solution or in $0.85 \%$ saline solution (negative controls) for $5 \mathrm{~min}$. Subsequently, the excess liquid was removed and placed in plastic trays with cardboard beds for fruit packaging. The trays were covered with plastic film and arranged in an ambient chamber regulated at $21{ }^{\circ} \mathrm{C}$, relative humidity of $40 \%$ and darkness, for 10 and 30 days. Other mango fruits were sprayed with approximately $15 \mathrm{~mL}$ of $C$. gloeosporioides spore solution $\left(1 \times 10^{6}\right.$ spores $\left./ \mathrm{mL}\right)$ or saline solution (positive control to infection). Finally, to evaluate the antagonistic effect of chitosan on C. gloeosporioides infection, mango fruits treated $24 \mathrm{~h}$ prior to chitosan were sprayed with spore suspension of $C$. gloeosporioides and incubated in an environmental chamber. All treatments were performed in quadruplicate ( $\mathrm{n}=4$ mangos per replicate). Photographs were taken of the mangoes after incubation to determine the disease progression. 
After treatment, the mangoes were dissected to separate two portions of pulp from the seed. With a bronze punch, 6 cylinders of the fruit were obtained with $1 \mathrm{~cm}$ in diameter, distributed randomly along the pulp sections. Subsequently, the exocarp (cuticle or peel) and mesocarp (pulp) were separated and collected separately, taking $13 \mathrm{~mm}$ of the cylinder adjacent to the peel. Samples from each of the mangos represented individual samples.

The exocarp (peel) and mesocarp (pulp) of the sampled mangoes were rapidly frozen by immersion in liquid nitrogen and ground in mortar until a pulverized sample was obtained. The ground samples were stored separately in plastic bottles at a temperature of $-40{ }^{\circ} \mathrm{C}$ for further evaluation.

\section{Determination of total phenolic contents}

$200 \mathrm{mg}$ of pulverized pulp or peel was taken and $500 \mu \mathrm{l}$ of a mixture of ethanol: methanol $(1: 1, \mathrm{v} / \mathrm{v})$ was added, mixed vigorously and incubated with stirring for $30 \mathrm{~min}$ at $25{ }^{\circ} \mathrm{C}$. The samples were then centrifuged for $10 \mathrm{~min}$ at 13,000 rpm, collecting the supernatant. The extraction process was repeated with the sediment, collecting the supernatants of each cycle ( 3 cycles in total). The organic extracts obtained were dried in a rotary evaporator under vacuum at an absolute pressure of $400 \mathrm{~mm} \mathrm{Hg}$ and $45^{\circ} \mathrm{C}$ for $20 \mathrm{~min}$. The dried samples were resuspended in $500 \mu \mathrm{L}$ of deionized and degasified water. The determination of phenolic compounds was carried out by the Folin-Ciocalteu method. ${ }^{29}$

Then $20 \mu \mathrm{l}$ of the sample was mixed in $1.58 \mathrm{~mL}$ of water and 100 $\mu \mathrm{L}$ of the Folin-Ciocalteu reagent, and vigorously mixed for $10 \mathrm{~min}$. $300 \mu \mathrm{l}$ of $20 \%$ sodium carbonate was added, mixed and incubated for 2 hours at $25{ }^{\circ} \mathrm{C}$. The absorbance at a wavelength $\lambda=765 \mathrm{~nm}$ was measured. The results were reported in $\mathrm{g}$ of phenols $/ \mathrm{kg}$ expressed as fresh weight using a calibration curve generated using pyrocatechol.

\section{Determination of the moisture content of the fruit, titratable acidity and $\mathrm{pH}$}

The treated mangoes were weighed during the experiment $(0,10$ and 30 days of treatment) and the weight difference was calculated according to the following equation:

$$
\text { Moisture content }=\frac{(\text { final weight }- \text { initial weigh })}{\text { initial weigh }} \times 100 \%
$$

The determination of the acidity was carried out by means of titration by sodium hydroxide $(\mathrm{NaOH}) 0.1 \mathrm{~N}$ (Diario Oficial de la Federación, 1978), using $0.75 \%$ phenolphthalein as an indicator. $5 \mathrm{~g}$ of fresh pulp was homogenized with $50 \mathrm{~mL}$ of deionized water for 60 s. The mixture was filtered through 4 layers of gauze and the filtrate was collected. $10 \mathrm{~mL}$ of the filtered juice were titrated and the data were reported as $\mathrm{mL}$ of $\mathrm{NaOH} 0.1 \mathrm{~N}$ consumed/100 g of pulp. The $\mathrm{pH}$ was determined with a portable potentiometer.

\section{Determination of the profiles of reducing sugars in pulp}

$100 \mathrm{mg}$ of pulverized pulp was taken and $1000 \mu \mathrm{L}$ of distilled water was added. The mixture was vigorously shaken and incubated at 50 ${ }^{\circ} \mathrm{C}$ for $15 \mathrm{~min}$. The suspension was centrifuged at $13,000 \mathrm{rpm}$ for 15 min and the supernatant was recovered. The pellet was resuspended with $1000 \mu \mathrm{L}$ of distilled water, repeating the process. The tubes were centrifuged again at 13,000 rpm for $15 \mathrm{~min}$. The two supernatants of each sample were mixed. Reducing sugars were determined by the colorimetric method of Dinitrosalicylic Acid. ${ }^{32} 300 \mu \mathrm{L}$ of $1 \%$ DNS solution and $300 \mu \mathrm{L}$ of the sample were added. The tubes were heated to $90{ }^{\circ} \mathrm{C}$ for $15 \mathrm{~min}$, the samples were allowed to cool to room temperature and $100 \mu \mathrm{L}$ of $40 \%$ sodium tartrate solution was added. The absorbance of the samples was measured at a wavelength of $\lambda$ $=575 \mathrm{Nm}$, using a visible light spectrophotometer. The reducing sugar concentration of each sample was calculated using the linear regression adjustment obtained from the glucose standards, reporting them as glucose $/ \mathrm{kg}$ fresh weight.

\section{Determination of sugarlacid ratio}

To determine the degree of maturity of the fruits submitted to the different treatments, the ratio between the concentration of reducing sugars and the titratable acidity was calculated according to the following equation:

Sugar $/$ acid ratio $=\frac{\text { Reducing sugars }(\mathrm{mg} \text { glucose } / \mathrm{g} \text { fresh weigh })}{\text { titratable acidity }(\mathrm{mg} \text { citric acid } / \mathrm{g} \text { fresh } \text { weigh })}$

The ratio in equivalent grams of glucose was reported on equivalent grams of citric acid. For the conversion of units to the titratable acidity, the conversion factor was used $1 \mathrm{~mL}$ of $0.1 \mathrm{~N} \mathrm{NaOH}$ consumed equals $0.006404 \mathrm{~g}$ of anhydrous citric acid. ${ }^{33}$

The quantitative values of the physicochemical and biochemical tests of the chitosan bioassays were represented as means \pm Standard Deviation of the replicates of each treatment. Statistical differences were determined using an ANOVA test using the Holm-Sidak algorithm, with a significance level of $\mathrm{P}<0.005$. Statistical analysis was performed using SigmaStat v. 3.1 (Systat Software Inc., San Jose, CA, USA)

\section{Results and discussion}

As is shown in Figure 1A, crude extracts obtained with hexane were generally more effective in inhibiting the growth of mycelium of C. gloeosporioides (Figure 1B). Among peel extracts, C. aurantium had the most effective antifungal effect, with concentrations as low as $250 \mu \mathrm{g} / \mathrm{ml}$ inhibiting at least 3 times the growth of mycelial diameter than observed in the bioassays with the crude extracts of grapefruit and tangerine (Figure 1B). This represents $75 \%$ inhibition of growth, much higher than that reported by Hernández-Albíter (19) who report a $40 \%$ reduction in germination of conidia of this phytopathogen when applying crude extracts of Citrus aurantium at different concentrations to conidial dilutions and Madhuri y cols. (20), who proved that the methanolic extracts of sour orange inhibited mycelial growth to $>50 \%$ of $C$. capsici.

With respect to the treatment with chitosan, it was observed that all the fruits presented have a similar appearance to the $10 \mathrm{~d}$ post incubation (Figure 2A). However, at 30 days and specially in the fruits exposed only to the solution of spores of C. gloeosporioides, it is possible to note the presence of lesions characteristic of anthracnose, such as the appearance of spots on the epidermis and the darkening of the layer surface of the pulp. On the contrary, in fruits treated with chitosan prior to inoculation with the phytopathogen, these lesions are not observed so markedly (Figure 2A).

The analysis of the total phenol concentration showed a greater amount of these compounds in the pulp of the mangos treated with chitosan (Figure 2B) in contrast to the treatment with the phytopathogen only, where no appreciable increase of these compounds was observed. The effect detected in chitosan treatment was noticed even in the treatment with chitosan and the phytopathogen (Figure 2B, treatment 5), suggesting that chitosan causes some change in fruit metabolism, inducing the production of these compounds. 
(A)

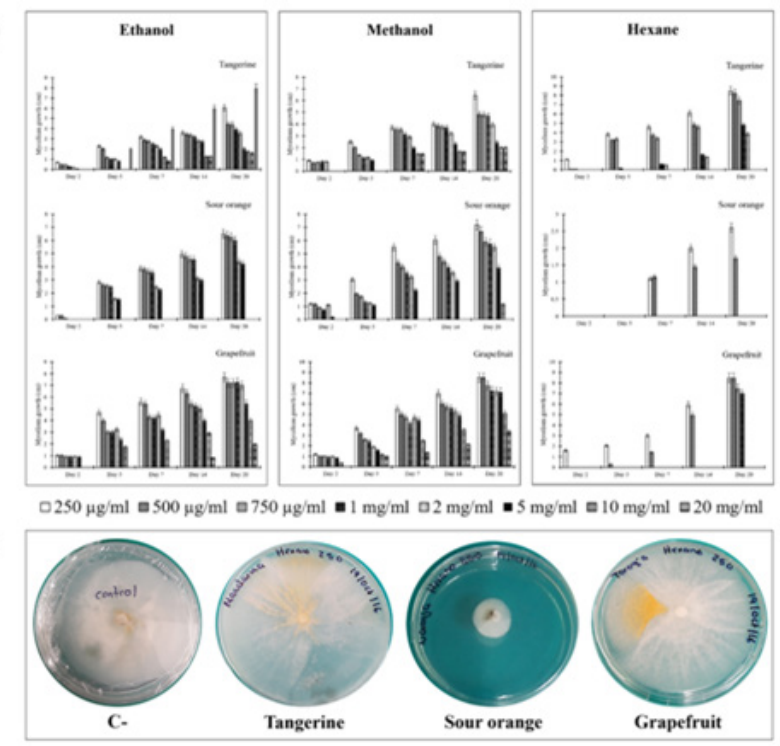

Figure I (A) Effect of organic extracts obtained with ethanol, methanol and hexane from dried peels of tangerine, sour orange and grapefruit on the growth of mycelium of Colletotrichum gloesporioides.(B) Effect of different concentrations after 20 days of the crude extract obtained with hexane from sour orange dried peels on linear growth $(\mathrm{cm})$ of the mycelium of $C$. gloeosporioides. C-: Negative control (sterile water).

(A)

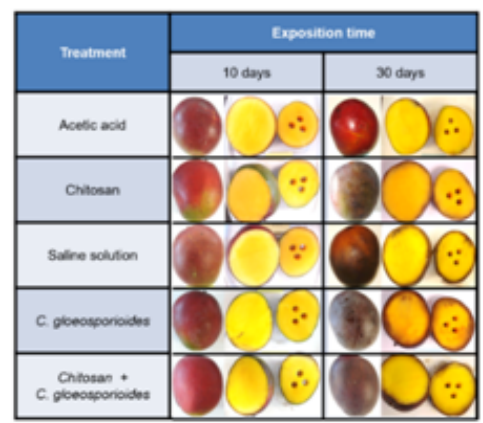

(B)

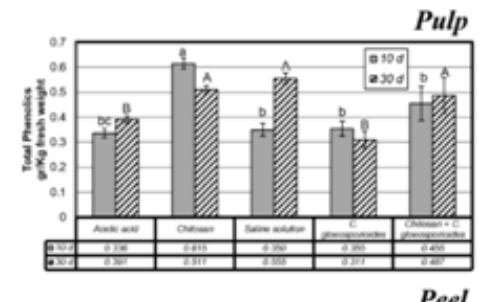

(C)

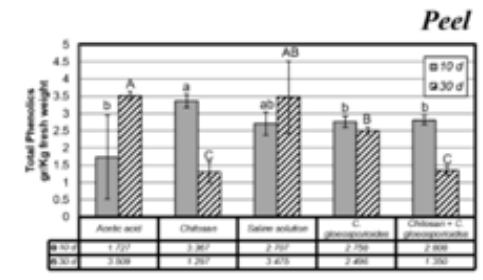

Figure $2 \mathrm{~A}$ ) Physical appearance of fruits after different treatments for 10 and 30 days (d). B) Concentrations of total soluble phenols in mango fruit pulp subjected to different treatments and incubated for $10 \mathrm{~d}$ (gray bar) and $30 \mathrm{~d}$ (shaded bars). C) Concentrations of total soluble phenols in mango fruit peel submitted to different surface treatments and incubated for $10 \mathrm{~d}$ (gray bar) and $30 \mathrm{~d}$ (shaded bars). Bars with different letters means significant differences, resulting from one-way ANOVA $(P<0.005)$.
As can be seen in Figure 2C, the concentration of total phenols is much higher in the skin compared to the pulp. It was observed that the amount of total phenols in the skin decreased drastically in treatments that included exposure to chitosan, with the lowest phenol levels at $30 \mathrm{~d}$ of incubation (Figure 2C, treatment 2). This effect was not observed in fruit skin inoculated only with $C$. gloeosporioides, where no changes were induced in total phenol content (Figure 2C, treatment 4). However, in mangoes treated with chitosan and subsequently with phytopathogen present a dramatic decrease in total phenol content (Figure 2C, treatment 5).

Regarding the loss of moisture, during the first 10 days of treatment no statistically significant differences were observed in this variable, losing on average between 2.00 and $2.55 \%$ of humidity with these treatments (Figure 3A). During the second sampling (30 days) it was observed that the mangos treated with a chitosan coating showed a loss of moisture lower than those to which it was not applied. Specifically, fruits treated with chitosan exhibited a loss of moisture of $5.22 \%$ (Fig. 3A, treatment 2) while their negative control (acetic acid solution without chitosan) had a moisture loss of $8.62 \%$ (Figure $3 \mathrm{~A}$, treatment 1 ).

(A)

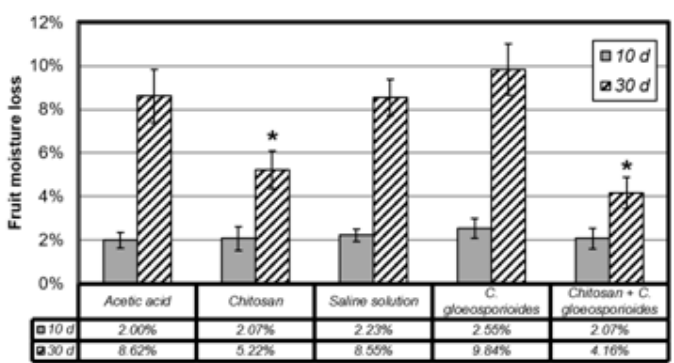

(B)

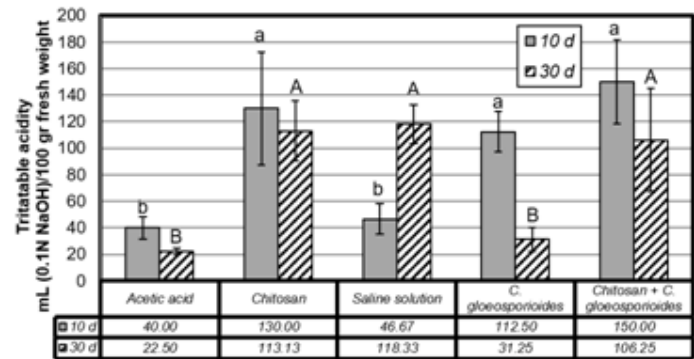

Figure 3 A) Moisture loss in mango fruits subjected to different treatments and incubated for $10 \mathrm{~d}$ (gray bar) and $30 \mathrm{~d}$ (shaded bars). Asterisks indicate significant differences, resulting from one-way ANOVA $(P<0.005)$. B $)$ Titratable acidity contents of mango pulp on fruits submitted to the different treatments and incubated for $10 \mathrm{~d}$ (gray bar) and $30 \mathrm{~d}$ (shaded bars).Bars with different letters means significant differences, resulting from One-Way ANOVA ( $P<0.005)$.

The protective effect of chitosan coating on mango fruits was consistent with that expected from an organic coating ${ }^{23}$ preventing moisture loss and weight in the post-harvest stage. The fruits inoculated with C. gloeosporioides showed the highest moisture loss, $9.84 \%$ (Figure $3 \mathrm{~A}$, treatment 4 ), an event associated with the induction of fruit maturation due to the presence of the phytopathogen (3). In turn, it was observed that chitosan-treated mango fruits inoculated with the phytopathogen had the lowest moisture loss, suggesting that the coating with chitosan had a protective effect on the fruit against infection with C. gloeosporioides.

It should be noted that the protective effect of chitosan was reached with a much lower concentration $(0.25 \%)$ and at a higher 
temperature $\left(2{ }^{\circ} \mathrm{C}\right)$ than that commonly used in existing reports $(15$ ${ }^{\circ} \mathrm{C}$ ), where the protective effect on mango fruit quality (cv. Tainong) was demonstrated at $2 \%{ }^{35}$ or only through in vitro bioassays. ${ }^{36}$

When analyzing the titratable acidity present in the pulp of treated mango fruits, it was observed that infection with $C$. gloeosporioides produces alkalinization of the pulp at $30 \mathrm{~d}$ of treatment (Figure $3 \mathrm{~B}$, treatment 4). Over time, this alkalinization was presented to a lesser extent in the treatments in which chitosan was applied, which suggests a decrease in the ripening rate when the fruits are treated with this compound, especially if the previous treatment is performed previous the infection with C. gloeosporioides (Figure 3B, treatment 5 ). When measuring the $\mathrm{pH}$ of mango pulp, it was observed that only the treatment with $C$. gloeosporioides causes alkalinization of the tissue (from 4.06 on day 10 to 5.0 on day 30, data not shown).

This data together with the effect observed in the determination of titratable acidity of mango fruits at $30 \mathrm{~d}$ of treatment, indicates that both the acidity due to the presence of organic acids and that due to the release of hydrogen ions were affected by the infection of the plant pathogen. Organic acids (tartaric, citric, succinic), essential components in the tricarboxylic acid cycle, are metabolized during fruit respiration. ${ }^{35} \mathrm{~A}$ decrease in acidity has been observed during ripening of many fruits, suggesting the existence of considerable metabolic rates at this stage. ${ }^{36}$ At the same time, organic acids and their derivatives contribute greatly to the taste, with a strong correlation between the sugar: acid balance and the sensorial perception of the consumer in the different species of fruit trees. ${ }^{37}$ It is noteworthy that the treatments that included the coating with chitosan maintained the acidity of the pulp, whereas the positive control of infection with C. gloeosporioides decreased the acidity of the fruit, suggesting an increase in the consumption of organic acids as a consequence of the invasion of the fungus in the pulp.

The sweetness of the mangoes is an important parameter of their quality and is correlated with the degree of ripening of the fruits and the sugar/acid ratio. Evaluating this factor in the pulp of the fruits submitted to the different treatments, it was observed that during the first $10 \mathrm{~d}$ the treatment with chitosan induced a slight increase in the concentration of reducing sugars, compared to the other treatments (Figure 4A, treatments 2 and 5). However, at longer incubation time, it was observed that this condition was reversed, with chitosantreated mangoes having the lowest concentration of reducing sugars in the pulp (Figure 4A, treatments 2 and 5). Negative controls (acetic acid) showed a gradual increase in the concentration of reducing sugars, which is to be expected in the normal fruit ripening process. Those mangoes that were infected with $C$. gloeosporioides showed a dramatic increase in the concentration of reducing sugars at 30 $\mathrm{d}$, suggesting the induction of fruit ripening resulting from the development of the disease. However, it is important to note that in the fruits that were coated with chitosan prior to the inoculation with the phytopathogen, a significant increase in the reducing sugars was not observed throughout the experiment, suggesting a retarding effect of the fruit maturation and the development of anthracnose (Figure $4 \mathrm{~A}$, treatment 5).

As can be seen in Figure 4B, the sugar/acid ratio increases during the experiment in the negative controls (acetic acid and saline). This provide experimental evidence about the development of fruit maturation, which involves the consumption of organic acids increasing the respiration rate as well as a cleavage of reserve polysaccharides and the production of simple sugars.

In fact, the values of the sugar/acidity ratio in the chitosan-coated fruits are statistically lower than those without chitosan, maintaining a constant maturity rate up to $30 \mathrm{~d}$ of treatment, even in fruits inoculated with phytopathogen spores (Figure 4B, treatment 5).
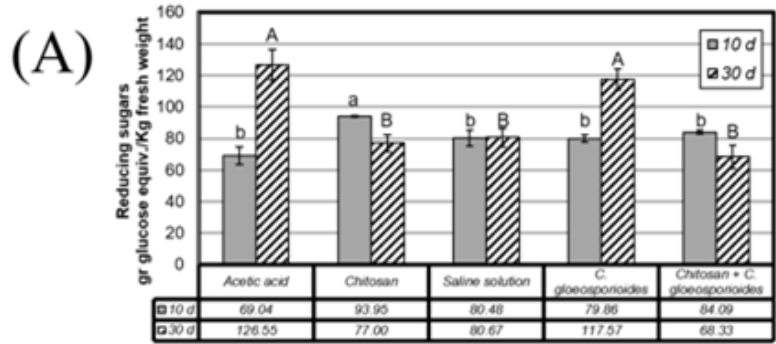

(B)

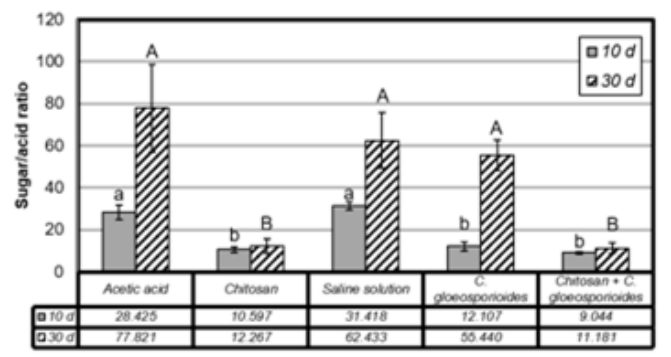

Figure 4 A) Concentrations of reducing sugars in the pulp in mango fruits submitted to different treatments and incubated for $10 \mathrm{~d}$ (gray bar) and $30 \mathrm{~d}$ (shaded bars). B) Sugar/acid ratio in the pulp in mango fruits submitted to the different treatments and incubated for $10 \mathrm{~d}$ (gray bar) and $30 \mathrm{~d}$ (shaded bars). Bars with different letters means significant differences, resulting from OneWay ANOVA ( $P$ <0.005).

It is also possible to observe that infection with phytopathogen causes a greater increase in sugar/acidity ratio, suggesting an accelerated cleavage of reserve polysaccharides by the action of the hydrolytic enzymes of the invasive fungus. ${ }^{37}$

It has been shown that the coating with chitosan forms an effective barrier against the loss of moisture and volatile organic compounds in strawberries and other fruits, resulting in an increase in shelf life. ${ }^{23,26,27,34}$ This suggests that this barrier could interfere with the natural metabolism of the fruit altering the respiration rate and the production of ethylene resulting in a delay in maturation.

In conclusión, the citrus peels are considered waste products. Our results indicate that the peels of the Citrus species bioassayed present antimicrobial properties. Specifically, the peel extracts of C. aurantium obtained with hexane showed the higher bioactivity against $C$. gloeosporioides from a dose of $250 \square \mathrm{g} / \mathrm{ml}$. Therefore, it is possible to postulate that the peels of this citrus fruit can be used to obtain extracts that could be applicable for field and post-harvest control of anthracnose. However, it is necessary to carry out new field/ in vivo bioassays to verify its usefulness in the control of this disease.

Additionally, the results show that the coating with chitosan applied to mango fruits has a protective effect to the infection with C. gloeosporioides, increasing the shelf life of the fruit under storage conditions. It should be noted that the mango is a climacteric fruit, which implies that the maturation process is triggered by a sudden increase in the rate of respiration and ethylene production, so postharvest management strategies aimed at the prolongation of shelf life are of special interest for the agroindustrial chain of this fruit, which usually involves long periods of storage in cold with the objective of delaying the maturation of the fruit increasing the costs of production and diminishing the profit margin of the intermediary. This is the first work that reports the increase in shelf life of this product, in 
environmental condition exposed to the phytopathogen causing anthracnose, by organic methods free of agrochemicals.

\section{Acknowledgements}

This work was supported by the Tecnológico Nacional de México [Grant number 254.15-PD].

\section{Conflicts of interest}

Authors declare no conflict to of interest exists.

\section{References}

1. Food and agriculture organization of the united nations. FAOSTAT [Internet]. 2017.

2. Flórez OA, Marín HF, Zapata JA. Estudio de las prácticas de cosecha y poscosecha de la papaya (Carica papaya cv. Maradol), en el Departamento del Huila, Colombia. Rev Investig Agrar Ambient RIAA. 2015;1(1):29-36.

3. Swamy JS. Anthracnose-a devastating pre and post-harvest disease in mango. Int J Plant Prot. 2012;5(2):429-437.

4. Pérez Castro LM, Saquero MJ, Beltrán Herrera JD. Caracterización morfológica y patogénica de Colletotrichum sp. como agente causal de la antracnosis en ñame Dioscorea sp. Rev Colomb Biotecnol. 2003;1(1):24-35.

5. Mohana DC, Raveesha KA. Anti-fungal evaluation of some plant extracts against some plant pathogenic field and storage fungi. J Agric Technol. 2007;4(1):119-137.

6. Rakesh K, Dileep N, Junaid S, et al. Inhibitory effect of cow urine extracts of selected plants against pathogens causing rhizome rot of ginger. Sci Technol Arts Res J. 2013;2(2):92.

7. Velázquez-Nuñez MJ, Avila-Sosa R, Palou E, et al. Antifungal activity of orange (Citrus sinensis var. Valencia) peel essential oil applied by direct addition or vapor contact. Food Control. 2013;31(1):1-4

8. Yashoda K, Manasa M, Vivek MN, et al. Inhibitory effect of some plants of western ghats of karnataka against colletotrichum capsici. Sci Technol Arts Res J. 2014;3(2):76.

9. Jing L, Lei Z, Li L, et al. Antifungal activity of citrus essential oils. $J$ Agric Food Chem. 2014;62(14):3011-3033.

10. Phillips CA, Laird K, Allen SC. The use of Citri-VTM ${ }^{\circledR}$ - An antimicrobial citrus essential oil vapour for the control of Penicillium chrysogenum, Aspergillus niger and Alternaria alternata in vitro and on food. Food Res Int. julio de. 2012;47(2):310-304.

11. Singh P, Shukla R, Prakash B, et al. Chemical profile, antifungal, antiaflatoxigenic and antioxidant activity of Citrus maxima Burm. and Citrus sinensis (L.) Osbeck essential oils and their cyclic monoterpene, DL-limonene. Food Chem Toxicol. 2010;48(6):1734-40.

12. Viuda-Martos M, Ruiz-Navajas Y, Fernández-López J, et al. Antifunga activity of lemon (Citrus lemon L.), mandarin (Citrus reticulata L.), grapefruit (Citrus paradisi L.) and orange (Citrus sinensis L.) essential oils. Food Control. 2008;19(12):1130-1138.

13. Poiana M, Sicari V, Mincione B. A comparison between the chemical composition of the oil, solvent extract and supercritical carbon dioxide extract of citrus medica cv. diamante. J Essent Oil Res. marzo de. 1998;10(2):145-152.

14. Chanthaphon S, Chanthachum S, Hongpattarakere T. Antimicrobial activities of essential oils and crude extracts from tropical Citrus spp. against food-related microorganisms. Songklanakarin J Sci Technol [Internet]. 2008;30.

15. Fisher K, Phillips C. Potential antimicrobial uses of essential oils in food: is citrus the answer?. Trends Food Sci Technol. 2008;19(3):156-164.

16. Harsha TS, Prashanth MS, Sandeepa KH, et al. Antifungal activity of leaf extract of three citrus plants against Colletotrichum capsici. Journal of Pharmaceutical \& Scientific Innovation. J Pharm Sci Innov 2014;3(4):369-370.

17. Hernández-Albíter RC, Barrera-Necha LL, Bautista-Baños S, et al. Antifungal potential of crude plant extracts on conidial germination of two isolates of colletotrichum gloeosporioides (Penz.) penz. and sacc. Rev Mex Fitopatol. 2007;25(2):180-185.

18. Madhuri S, Ashwini UH, Srilakshmi NS, et al. Antimicrobial activity of Citrus sinensis and Citrus aurantium peel extracts. J Pharm Sci Innov. 2014;3(4):366-368.

19. Rammanee K, Hongpattarakere T. Effects of tropical citrus essential oils on growth, aflatoxin production, and ultrastructure alterations of aspergillus flavus and aspergillus parasiticus. Food Bioprocess Technol. agosto de. 2011;4(6):1050-1059.

20. Olabarrieta I, Berasategui M, Iturriaga L, et al. Polnat II: Desarrollo de materiales anti microbianos de base biopolimérica para mejorar la conservación y seguridad de alimentos minimamente procesados. [Internet]. Dpto. Agricultura, Pesca y Alimentación-Gobierno Vasco (Sukarrieta, España). 2008.

21. González-Aguilar GA, Monroy-García I, Goycoolea-Valencia F, et al Cubiertas comestibles de quitosano. Una alternativa para prevenir el deterioro microbiano y conservar la calidad de papaya fresca cortada. Proc Simp "Nuevas Tecnol Conserv Envas Frutas Hortal Veg Frescos Cortados" Habana Cuba. 2005;121-133.

22. Rojas R, Vicente AA, Aguilar CN. Advances in preservation of fruits and vegetables with bioactive coatings. Bol Cent Pesqui Process Aliment [Internet]. 15 de diciembre de 2015;33(2).

23. de Oliveira CEV, Magnani M, de Sales CV, et al. Effects of postharvest treatment using chitosan from Mucor circinelloides on funga pathogenicity and quality of table grapes during storage. Food Microbiol. 2014:44:211-219.

24. López-Mata MA, Ruiz-Cruz S, Navarro-Preciado C, et al. Efecto de recubrimientos comestibles de quitosano en la reducción microbiana y conservación de la calidad de fresas. BIOtecnia. 2012;14(1):33-43.

25. Singh H, Al-samarai G, Syarhabil M. Exploitation of natural products as an alternative strategy to control postharvest fungal rotting of citrus. Int J Sci Res Publ. 2012;2(3):1-4.

26. Palma-Guerrero J, Lopez-Jimenez JA, Pérez-Berná AJ, et al. Membrane fluidity determines sensitivity of filamentous fungi to chitosan. Mol Microbiol. febrero de. 2010;75(4):1021-1032.

27. Raafat D, von Bargen $\mathrm{K}$, Haas A, et al. Insights into the mode of action of chitosan as an antibacterial compound. Appl Environ Microbiol. 2008;74(12):3764-3773.

28. Abril M, Curry KJ, Smith BJ, et al. Improved microassays used to test natural product-based and conventional fungicides on plant pathogenic fungi. Plant Dis. 2008;92(1):106-112.

29. Waterhouse AL. Determination of total phenolics. Curr Protoc Food Anal Chem. 2002

30. Miller GL. Use of dinitrosalicylic acid reagent for determination of reducing sugar. Anal Chem. 1959;31(3):426-428.

31. Diario oficial de la federación. NMX-F-102-S-1978. Determinación de la acidez titulable en productos elaborados a partir de frutas y hortalizas. 1978.

32. Cáceres I, Martínez Jávega JM, Cuquerella J, et al. Influencia del encerado en la calidad de la mandarina Clemenules procedentes de Sistemas de Producción Integrada. Rev Iberoam Tecnol Postcosecha [Internet]. 2003;5(2). 
33. Zhu X, Wang Q, Cao J, et al. Effects of chitosan coating on postharvest quality of mango (Mangifera indica L. cv. Tainong) fruits. J Food Process Preserv. 2008;32(5):770-784.

34. Abd-AllA M, Wafaa M. New safe methods for controlling anthracnose disease of mango (Mangifera indica L.) fruits caused by Colletotrichum gloeosporioides (Penz.). J Am Sci. 2010;8(8):361-367.
35. Kays SJ, Mohammed M, Benítez CE, et al. Postharvest biology. IICA, Port of Spain (Trinidad and Tobago); 2004.

36. Guzmán R, Segura R, Guzman ER, Segura E. Tecnología de frutas y hortalizas. 2001

37. Wills RHH, Lee TH, Graham D, et al. Postharvest. An introduction to the physiology and handling of fruit and vegetables. Granada.; 1981. 